\section{Prevalence of Musculoskeletal Pain among Orthopedic Surgeons in North West Region of Saudi Arabia: A Cross-Sectional Study}

\section{Linah Z Aljohani'*, Sultan S Batayyib', Khaled M Ghabban², Meshal Y Koshok ${ }^{3}$, Abdulmuhsen N Alshammari}

${ }^{1}$ Department of Orthopedics, King Fahad General Hospital, Almadinah Almunawwarah, Saudi Arabia

${ }^{2}$ Department of Orthopedics, King Salman Armed Forces Hospital, Tabuk, Saudi Arabia

${ }^{3}$ Department of Orthopedics, Almadinah Almunawwarah Hospital, Almadinah Almunawwarah, Saudi Arabia

\begin{abstract}
Objectives: Orthopedic practice is highly demanding mentally and physically, musculoskeletal (MSK) pain is common among orthopedic surgeons. We believe that studies related to MSK disorders among orthopedic surgeons in Saudi Arabia are relatively few. Our study will investigate the prevalence and predictor factors of MSK disorders among orthopedic surgeons in North-West Region of Saudi Arabia.

Methods: A cross-sectional study was conducted in Almadinah Almunawwarah and Tabuk cities. A total of 140 male and female orthopedic surgeons from different nationalities and subspecialties were requested to answer an online-based musculoskeletal Nordic questionnaire.
\end{abstract}

Results: A total of 97 participants completed the survey. The majority were from Almadinah Almunawwarah, and $92 \%$ were males. The highest responses of pain were those with lower back pain $85.4 \%$, followed by neck pain $37.5 \%$. Around $23 \%$ of the responders have experienced MSK pain for more than six months and $9.3 \%$ experience MSK pain more than five times per week. Some of the participants were tried rest to relieve the pain in the prevalence

*Corresponding author: Linah Z Aljohani, Department of Orthopedics, King Fahad General Hospital, Almadinah Almunawwarah, Saudi Arabia, E-mail: Leno912008@gmail.com

Citation: Aljohani LZ, Batayyib SS, Ghabban KM, Koshok MY, Alshammari AN (2019) Prevalence of Musculoskeletal Pain among Orthopedic Surgeons in North West Region of Saudi Arabia: A Cross-Sectional Study. J Orthop Res Physiother 6: 050 .

Received: August 21, 2020; Accepted: August 26, 2020; Published: September 03, 2020

Copyright: (C) 2020 Aljohani LZ, et al. This is an open-access article distributed under the terms of the Creative Commons Attribution License, which permits unrestricted use, distribution, and reproduction in any medium, provided the original author and source are credited. of $22.7 \%$ and $13.4 \%$ of them seek medical advice for once. Only $22.7 \%$ of the responders reported that MSK pain is affecting their life.

Conclusion: The prevalence of work-related MSK disorders among orthopedic surgeons is higher than general population in Saudi Arabia. Low back pain and neck pain is the most MSK pain reported by participants. More studies with generalizable designs and larger samples needed to investigate different risk factors that may contribute to the development of MSK pain among orthopedic surgeons.

Keywords: Musculoskeletal; Orthopedic; Pain; Prevalence; Saudi Arabia; Workplace

\section{Introduction}

Work-related musculoskeletal disorders entail a wide range of inflammatory and degenerative conditions that are caused by work-related activities. It affects joints, musculo-ligamentous and neurovascular structures causing pain and functional impairment resulting in economic cost to the workforces [1]. Musculoskeletal (MSK) disorders are responsible for increasing working compensation, health costs, reduced productivity, and lower quality of life. They also cause loss of work time or absences, change career, and disabilities [2].

Orthopedic surgery practice is highly demanding, mentally, and physically. Multiple repetitive maneuvers and movements such as prolonged standing, postures, and handling with heavy tools in operation rooms, all these will cause adverse effects on the musculoskeletal system, especially with those who have risk factors for developing MSK disorders such as smoking, obesity, and sedentary lifestyle $[3,4]$.

A study of AL Qahtani et al. showed the prevalence of MSK disorders in orthopedic trauma surgeons in North America; it concluded that the vast majority of MSK disorders and complaints were due to lower back pain [3]. A study of Auerbach D et al. regarding spine surgeons concluded that spine surgeons have a higher prevalence of MSK disorders compared to disease estimates in the general population [5]. Al-Mohrej et al. study showed the majority of MSK pain sites in orthopedic surgeons in Riyadh are lower back and neck pain, respectively. Age, smoking, Body Mass Index (BMI), and years of experience were correlated with considerable problems [6].

We believe that studies related to MSK disorders among orthopedic surgeons in Saudi Arabia are relatively few. Our study aims to investigate the prevalence of MSK disorders among orthopedic surgeons in North West region of Saudi Arabia through a survey distribution as it will assess the potential risk factors and predictors.

\section{Materials and Methods}

This cross-sectional study was conducted in North-west region of Saudi Arabia; the two largest cities, Almadinah Almunawwarah and Tabuk cities. The survey was distributed via electronic communication 
Citation: Aljohani LZ, Batayyib SS, Ghabban KM, Koshok MY, Alshammari AN (2019) Prevalence of Musculoskeletal Pain among Orthopedic Surgeons in North West Region of Saudi Arabia: A Cross-Sectional Study. J Orthop Res Physiother 6: 050.

to all orthopedic surgeons in Almadinah Almunawwarah and Tabuk (total of 140), participant responded (69.3\%). Male and female orthopedic surgeons from different nationalities were included in the study. Orthopedic surgeons with less than one-year experience were excluded.

During a one-month period, orthopedic surgeons were asked to answer an MSK Nordic questionnaire, and its reliability and validity were tested [7]. The questionnaire consisted of 24-items and was developed to assess their answers regarding MSK disorders.

The demographics include gender, age, marital status, nationality, and years of experience.

\section{Statistical analysis}

Our questionnaire was designed using Google forms (Google Inc.). Data collected were then migrated to a CSV file, used and analyzed with Statistical Package for the Social Sciences program (SPSS), version 22.0 (IBM, Armonk, New York, USA) for descriptive statistics.

\section{Results}

Among 97 participants who completed the survey, most of them were from Almadinah Almunawwarah and the rest from Tabuk. Almost $93 \%$ of the participants were male, and 76 (78.4\%) were married. In all $50(51.5 \%)$ were Saudis, and the rest were from different nationalities (Table 1). The BMI was between 25 to 29.9 in $38(39.2 \%)$ of the participants where it was between 18.5 to 24.9 in 29 $(29.9 \%), 27(27.8 \%)$ were more than 30 and $3(3.1 \%)$ were less than 18.5 .

\begin{tabular}{|l|c|c|}
\hline Nationality & Frequency & Percent \\
\hline Saudi & 50 & $51.5 \%$ \\
\hline Egyptian & 29 & $25.9 \%$ \\
\hline Syrian & 3 & $31 \%$ \\
\hline Pakistani & 5 & $52 \%$ \\
\hline Yemeni & 2 & $21 \%$ \\
\hline Jordanian & 3 & $31 \%$ \\
\hline Sudanese & 3 & $31 \%$ \\
\hline Afghani & 1 & $10 \%$ \\
\hline Mauritanian & 1 & $10 \%$ \\
\hline Total & 97 & \\
\hline
\end{tabular}

In addition, $40(41.2 \%)$ of the participants were smokers. Among the participants $47(48.5 \%)$ of them reported participating in sport, $26(26.8 \%)$ were playing exercise 3-5 times per week. Participants were practicing different kinds of exercises (Figure 1). The sample consisted of $19(19.6 \%)$ consultants, 42(43.3\%) specialists, and the rest were residents with different levels of training. The study involved surgeons with various subspecialties, most of them were general orthopedic surgeon with prevalence $75.3 \%$, followed by trauma with prevalence $22.7 \%$ (Figure 2).
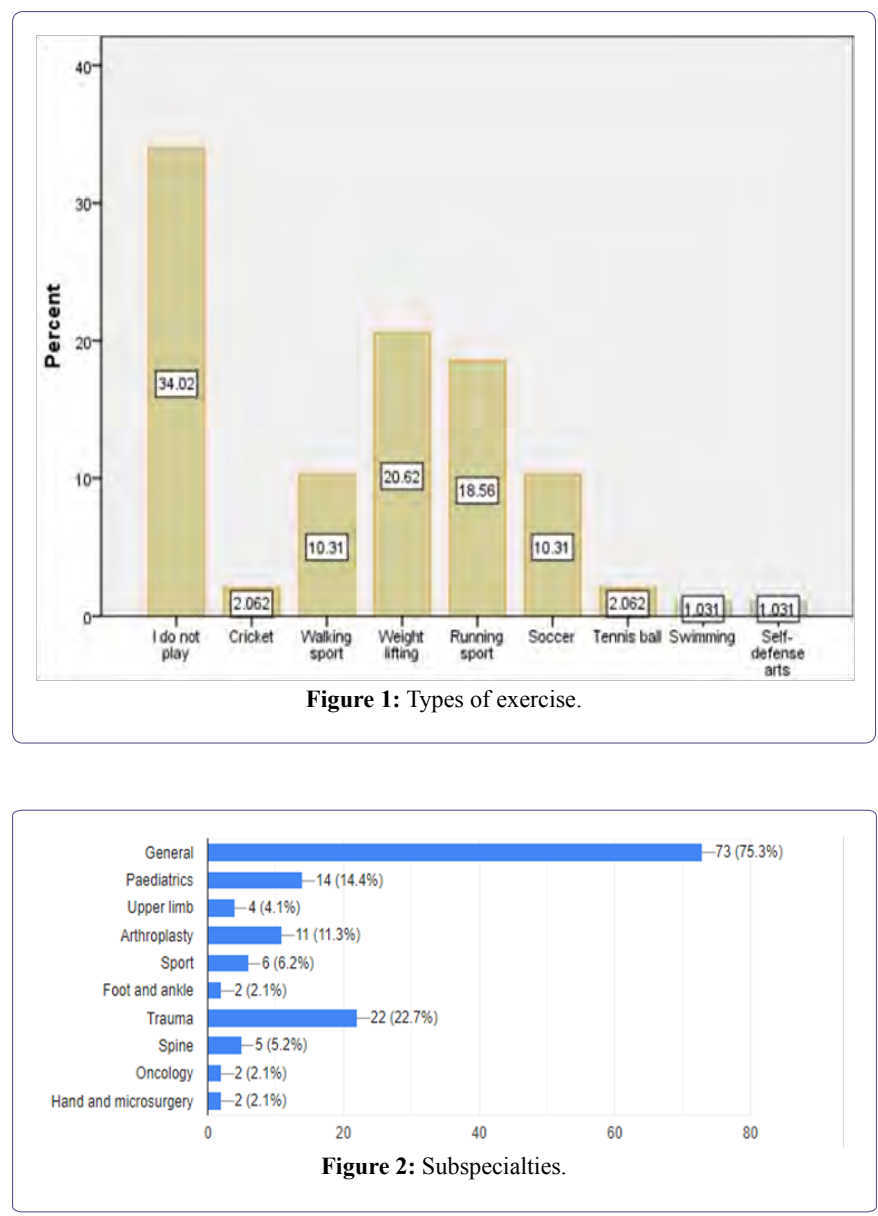

The prevalence of MSK pain was $49.5 \%$; lower back pain was the highest response of pain site with a prevalence of $85.4 \%$, followed by neck pain with a prevalence of $37.5 \%$. Furthermore, $33.3 \%$ have knee pain. Shoulder and elbow pain prevalence among $22.9 \%$ of the responders while foot/ankle pain and hand/wrist pain composed of $18.8 \%, 12.5 \%$ of the responses, respectively. Furthermore, $4.2 \%$ of responders experienced hip and thigh pain. Finally, $8.3 \%$ have all over body pain (Figure 3 ).

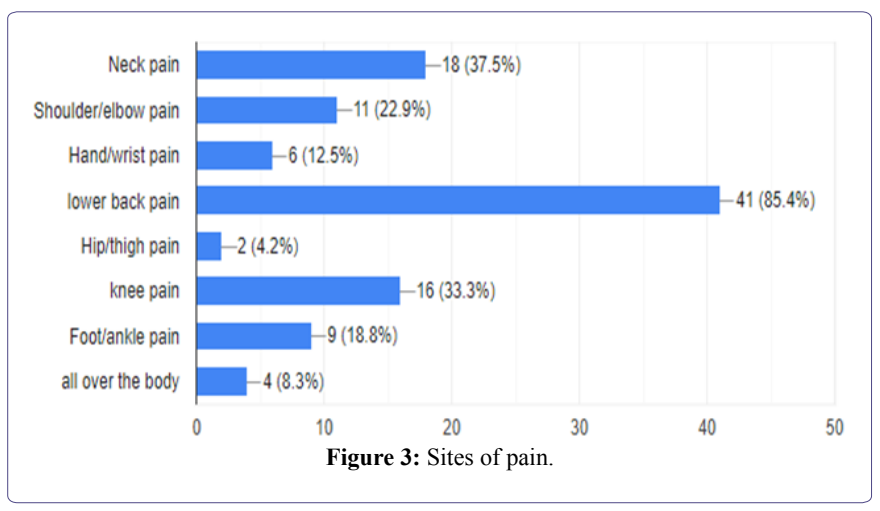


In addition, $22.7 \%$ of the responders have experienced MSK pain for more than six months, while $12.4 \%$ of them have the MSK pain for less than four weeks. The rest have reported the pain between 2 to 3 months and 3 to 6 months in prevalence $8.2 \%, 6.2 \%$, respectively. The response rate $(40.2 \%)$ of participants experienced MSK painless than five times per week, while $9.3 \%$ more than five times per week. The intensity of pain was mild in $25 \%$, moderate in $19.6 \%$, and severe in $4.1 \%$ according to the participant's responses. In all $28.9 \%$ of the participant responses that MSK pain is not affecting their life, while $20.6 \%$ affect their lives. During the last 12 months, most of the participants did not take sick leave due to MSK pain. Also, $7.2 \%$ of them took sick leave 1 to 5 times per year, while $1 \%$ took more than five times per year. The vast majority of the participants did not seek medical advice in prevalence of $28.9 \%$, while $13.4 \%$ of them seek medical advice for once. Furthermore, $4.1 \%$ and $3.1 \%$ seek medical advice twice and more than twice in respectively. About $22.7 \%$ of the participants were tried rest to relieve the pain, $20.6 \%$ tried medications, $5.2 \%$ tried physical therapy, and $1 \%$ tried surgery.

\section{Discussion}

There are various physical stresses and hazards applied to physicians in general, especially orthopedic surgeons [8] and it could be due to long work hours, repetitive movements, awkward postures, and challenges with instrument design [9], MSK pain is common among orthopedic surgeons [6].

As per Alshammari et al., $75.7 \%$ of the female residents and $89.4 \%$ of male residents in orthopedic training agreed that its physically exhausting specialty [10].

In comparison to other studies which were done in Riyadh (67\%) Canada (66\%) and India (50.7\%), MSK pain is lower in Almadinah Almunawwarah and Tabukcities $49.5 \%[2,3,6]$.

However, MSK pain is higher in orthopedic surgeons compared to the general population in Saudi Arabia, 25.4\% [11].

Moreover, the present study showed that the incidence of lower back pain (LBP) $85.4 \%$ among orthopedic surgeons, which is higher than the reported number of LBP in orthopedic residents in the united state $55 \%[8]$.

Neck pain prevalence is $37.5 \%$, which is less than reported result in Riyadh orthopedic surgeons 58.2\% [6].

Concluded that LBP and neck pain are the most reported MSK pain similar to the result conducted [6], which are also similar results have been obtained by Auerbach et al., that showed, lower back and neck pain were the most common pain in orthopaedic surgeons [5].

Similar results were conducted in more than one study in different cities and countries [5,6,12].

Which could lead to the conclusion that orthopedic surgeons could have LBP and neck pain due to long-standing hours in the operation room, which demands mechanical power. As using surgical instruments with repetitive hand movements can increase the risk of shoulder, elbow, and wrist problems $[11,13]$.

Moreover, increasing BMI increases the risk of foot and ankle pain among the surgeons, which is the same results conducted in other studies, as it could be due to mechanical and metabolic causes [6].
As orthopedic surgeries are usually required to stand for long hours in the operating room, increase weight could further increase the pressure on the lower limb.

Furthermore, we did not find any association between the age, years of experience, marital status, and MSK pain in our study, as conducted in other studies $[2,3,6]$. No clear association between smoking and MSK pain, which is different from the Al-Mohrej et al. study, which suggested a susceptible relationship between smoking,back, and hip/thigh pain in comparison with non-smokers [6].

In our sample, orthopedic surgeons who don't exercising complain from MSK pain more than others. From 33 surgeons who don't exercise 21 complaining from MSK pain, in comparison to 64 orthopedic surgeons who do different types of exercises, 27 of them complained from MSK pain. A study showed stretching and strength exercise in a continuous way it could reduce MSK pain. As exercising in daily routine could produce effective lifestyle changes to the physician [6].

Systematic review for articles done in English and Portuguese illustrated improvement in MSK pain with strength training. Strength exercises three times per week for at least 20 minutes, provide successful pain management [14].

In our study, we found that $74(76.3 \%)$ of the surgeons' careers restricted their time in playing a sport, which unfortunately affected their lifestyle. A lot of studies have concentrated on psychosocial aspects of choosing a surgical career, including personal interests, challenges, quality of life, burnout, and stress [2]. Moreover, 61\% choose orthopedic surgery based on their personal interest [15]. Nevertheless, almost half of the orthopedic surgeons have no relation between their interest in sports influence and career choice.

Moreover, the effect of MSK pain (49.4\%) on surgeons work was low as it affects them less than five times per week in 40 and $41 \%$ doesn't take any leave due to MSK pain in the last 12 months, while 20.6 of orthopedic surgeons seek medical advice which is lower than prevalence of orthopedic surgeons in Riyadh 30\% [6].

Our study has several limitations first, its cross-sectional design, which could limit the generalizability. Our sample may be small, where we need a more significant sample to be involved in more regions in the kingdom. Another limitation is that it's a survey-based, which depends on the self-reported nature of the data where it could affect reliability. Psychological risk factors weren't included in our study, which might also play a role in MSK pain, but we only focused on specific predictors of MSK pain.

\section{Recommendations}

In view of high prevalence, we recommend attention to application of ergonomics to work environment. This will aid in better workplace design, improved patient outcomes and ultimately lowering risks, and lowering healthcare worker-related costs.More analysis of MSK pain among orthopedic surgeons should be carried out. Future studies should investigate the physical and psychosocial predictors of initiation pain. Clinical evaluation should be included for surgeon's assessment as it's a more reliable source. 


\section{Conclusion}

The prevalence of work-related MSK disorders among orthopedic surgeons is higher than general population in Saudi Arabia. Low back pain and neck pain is the most MSK pain reported by participants.

\section{Source of Funding}

There is no source of funding for this publication.

\section{Conflict of Interest}

The authors have no conflict of interest to declare.

\section{References}

1. Korhan O, Mackieh A (2010) A model for occupational injury risk assessment of musculoskeletal discomfort and their frequencies in computer users. Safety Science 48: 868-877.

2. Yasobant S, Rajkumar P (2014) Work-Related musculoskeletal disorders among health care professionals: a cross-sectional assessment of risk factors in a tertiary Hospital, India. Indian J Occup Environ Med 18: 75.

3. AlQahtani SM, AlZahrani MM, Harvey EJ (2016) Prevalence of musculoskeletal disorders among orthopedic trauma surgeons: An OTA survey. Can J Surg 59: 42-47.

4. AlZahrani MM, AlQahtani SM, Tanzer M, Hamdy RC (2016) Musculoskeletal disorders among orthopedic pediatric surgeons: An overlooked entity. J Child Orthop 10: 461-466.

5. Auerbach JD, Weidner ZD, Milby AH, Diab M, Lonner BS (2011) Musculoskeletal disorders among spine surgeons: Results of a survey of the Scoliosis Research Society membership. Spine (Phila Pa 1976) 36: 17151721 .

6. Al-Mohrej OA, Elshaer AK, Al-Dakhil SS, Sayed AI, Aljohar S, et al. (2020) Work-related musculoskeletal disorders among Saudi orthopedic surgeons: A cross-sectional study. Bone \& Joint Open 1: 47-54.
7. Kuorinka I, Jonsson B, Kilbom A, Vinterberg H, Biering-Sørensen F, et al. (1987) Standardised Nordic questionnaires for the analysis of musculoskeletal symptoms. Appl Ergon 18: 233-237.

8. Knudsen ML, Ludewig PM, Braman JP (2014) Musculoskeletal pain in resident orthopaedic surgeons: Results of a novel survey. Iowa Orthop J 34: 190-196.

9. Epstein S, Sparer EH, Tran BN, Ruan QZ, Dennerlein JT, et al. (2018) Prevalence of work-related musculoskeletal disorders among surgeons and interventionalists: A systematic review and metaanalysis. JAMA Surg 153: e174947.

10. Alshammari AN, Shafiq MO, Altayeb MA, Khaja AF, Ghabban KM, et al. (2018) Gulf cooperation Council female residents in orthopedics: Influences, barriers, and mental pressures: A cross-sectional study. J Musculoskelet Surg Res 2: 51 .

11. Al-Arfaj AS, Alballa SR, Al-Dalaan AN, Al-Saleh SS, Al-Sekeit MA, et al (2003) Musculoskeletal pain in the community. Saudi Med J 24: 863-867.

12. Davis WT, Sathiyakumar V, Jahangir AA, Obremskey WT, Sethi MK (2013) Occupational injury among orthopaedic surgeons. J Bone Joint Surg Am 95: e107.

13. Barr AE, Barbe MF, Clark BD (2004) Work-Related musculoskeletal disorders of the hand and wrist: epidemiology, pathophysiology, and sensorimotor changes. J Orthop Sports Phys Ther 34: 610-627.

14. Rodrigues EV, Gomes ARS, Tanhoffer AIP, Leite N (2014) Effects of exercise on pain of musculoskeletal disorders: A systematic review. Acta Ortop Bras 22: 334-338.

15. Shafiq MO, Khaja AF, Alshammari AN, Altayeb MA, Ghabban KM, et al. (2019) The journey of orthopaedic surgery from residency to fellowship: A cross-sectional study in the Gulf Cooperation Council countries. J Taibah Univ Med Sci 14: 131-138. 


\section{di \\ нramb}

Advances In Industrial Biotechnology | ISSN: 2639-5665

Advances In Microbiology Research | ISSN: 2689-694X

Archives Of Surgery And Surgical Education | ISSN: 2689-3126

Archives Of Urology

Archives Of Zoological Studies | ISSN: 2640-7779

Current Trends Medical And Biological Engineering

International Journal Of Case Reports And Therapeutic Studies | ISSN: 2689-310X

Journal Of Addiction \& Addictive Disorders | ISSN: 2578-7276

Journal Of Agronomy \& Agricultural Science | ISSN: 2689-8292

Journal Of AIDS Clinical Research \& STDs | ISSN: 2572-7370

Journal Of Alcoholism Drug Abuse \& Substance Dependence | ISSN: 2572-9594

Journal Of Allergy Disorders \& Therapy | ISSN: 2470-749X

Journal Of Alternative Complementary \& Integrative Medicine | ISSN: 2470-7562

Journal Of Alzheimers \& Neurodegenerative Diseases | ISSN: 2572-9608

Journal Of Anesthesia \& Clinical Care | ISSN: 2378-8879

Journal Of Angiology \& Vascular Surgery | ISSN: 2572-7397

Journal Of Animal Research \& Veterinary Science | ISSN: 2639-3751

Journal Of Aquaculture \& Fisheries | ISSN: 2576-5523

Journal Of Atmospheric \& Earth Sciences | ISSN: 2689-8780

Journal Of Biotech Research \& Biochemistry

Journal Of Brain \& Neuroscience Research

Journal Of Cancer Biology \& Treatment | ISSN: 2470-7546

Journal Of Cardiology Study \& Research | ISSN: 2640-768X

Journal Of Cell Biology \& Cell Metabolism | ISSN: 2381-1943

Journal Of Clinical Dermatology \& Therapy | ISSN: 2378-8771

Journal Of Clinical Immunology \& Immunotherapy | ISSN: 2378-8844

Journal Of Clinical Studies \& Medical Case Reports | ISSN: 2378-8801

Journal Of Community Medicine \& Public Health Care | ISSN: 2381-1978

Journal Of Cytology \& Tissue Biology | ISSN: 2378-9107

Journal Of Dairy Research \& Technology | ISSN: 2688-9315

Journal Of Dentistry Oral Health \& Cosmesis | ISSN: 2473-6783

Journal Of Diabetes \& Metabolic Disorders | ISSN: 2381-201X

Journal Of Emergency Medicine Trauma \& Surgical Care | ISSN: 2378-8798

Journal Of Environmental Science Current Research | ISSN: 2643-5020

Journal Of Food Science \& Nutrition | ISSN: 2470-1076

Journal Of Forensic Legal \& Investigative Sciences | ISSN: 2473-733X

Journal Of Gastroenterology \& Hepatology Research | ISSN: 2574-2566
Journal Of Genetics \& Genomic Sciences | ISSN: 2574-2485

Journal Of Gerontology \& Geriatric Medicine | ISSN: 2381-8662

Journal Of Hematology Blood Transfusion \& Disorders | ISSN: 2572-2999

Journal Of Hospice \& Palliative Medical Care

Journal Of Human Endocrinology | ISSN: 2572-9640

Journal Of Infectious \& Non Infectious Diseases | ISSN: 2381-8654

Journal Of Internal Medicine \& Primary Healthcare | ISSN: 2574-2493

Journal Of Light \& Laser Current Trends

Journal Of Medicine Study \& Research | ISSN: 2639-5657

Journal Of Modern Chemical Sciences

Journal Of Nanotechnology Nanomedicine \& Nanobiotechnology | ISSN: 2381-2044 Journal Of Neonatology \& Clinical Pediatrics | ISSN: 2378-878X

Journal Of Nephrology \& Renal Therapy | ISSN: 2473-7313

Journal Of Non Invasive Vascular Investigation | ISSN: 2572-7400

Journal Of Nuclear Medicine Radiology \& Radiation Therapy | ISSN: 2572-7419

Journal Of Obesity \& Weight Loss | ISSN: 2473-7372

Journal Of Ophthalmology \& Clinical Research | ISSN: 2378-8887

Journal Of Orthopedic Research \& Physiotherapy | ISSN: 2381-2052

Journal Of Otolaryngology Head \& Neck Surgery | ISSN: 2573-010X

Journal Of Pathology Clinical \& Medical Research

Journal Of Pharmacology Pharmaceutics \& Pharmacovigilance | ISSN: 2639-5649

Journal Of Physical Medicine Rehabilitation \& Disabilities | ISSN: 2381-8670

Journal Of Plant Science Current Research | ISSN: 2639-3743

Journal Of Practical \& Professional Nursing | ISSN: 2639-5681

Journal Of Protein Research \& Bioinformatics

Journal Of Psychiatry Depression \& Anxiety | ISSN: 2573-0150

Journal Of Pulmonary Medicine \& Respiratory Research | ISSN: 2573-0177

Journal Of Reproductive Medicine Gynaecology \& Obstetrics | ISSN: 2574-2574

Journal Of Stem Cells Research Development \& Therapy | ISSN: 2381-2060

Journal Of Surgery Current Trends \& Innovations | ISSN: 2578-7284

Journal Of Toxicology Current Research | ISSN: 2639-3735

Journal Of Translational Science And Research

Journal Of Vaccines Research \& Vaccination | ISSN: 2573-0193

Journal Of Virology \& Antivirals

Sports Medicine And Injury Care Journal | ISSN: 2689-8829

Trends In Anatomy \& Physiology | ISSN: 2640-7752

Submit Your Manuscript: https://www.heraldopenaccess.us/submit-manuscript 